\title{
Narrativas de la crisis económica: el nacionalneoliberalismo en la publicidad española (2008-2017) ${ }^{1}$
}

\section{Francesc Xavier Ruiz-Collantes ${ }^{2}$ Cristina Sánchez-Sánchez ${ }^{3}$}

Recibido: 05/03/2018

Aprobado por pares: 25/04/2018
Enviado a pares: 13/03/2018

Aceptado: 06/11/2018

DOI: 10.5294/pacla.2019.22.2.8

\section{Para citar este artículo / to reference this article / para citar este artigo}

Ruiz-Collantes, F. X. y Sánchez-Sánchez, C. (2019). Narrativas de la crisis económica: el nacionalneoliberalismo en la publicidad española (2008-2017). Palabra Clave, 22(2), e2228. DOI: 10.5294/pacla.2019.22.2.8

\section{Resumen}

La publicidad, además de difundir discursos sobre productos y marcas, genera representaciones específicas de la sociedad. Teniendo en cuenta la crisis económica que atraviesa España desde 2008, esta investigación tiene como objetivo identificar cuáles son las narraciones que se han desarrollado acerca de dicha crisis en la publicidad española durante el periodo de 2008 a 2017. Mediante un cuestionario realizado a 45 profesionales del sector publicitario en España, se han identificado 31 spots que hacen referencia directa a la crisis. Estos spots han sido analizados mediante un análisis de contenido cualitativo inspirado en la semiótica narrativa. Los resultados muestran tres narrativas prototípicas dominantes que se articulan alrededor de dos ejes ideológicos: el nacionalismo y el neoliberalismo. No aparecen líneas argumentales acerca de las causas de la crisis ni de sus responsables y se traslada su solución a los ciudadanos, que deben salir de ella

1 Esta investigación surge dentro del proyecto "Héroes de la crisis: narrativa y discurso social en la cultura popular contemporánea” (CSO2014-56830-P), financiado por el Ministerio de Economía y Competitividad (Mineco) del Gobierno de España.

2 orcid.org/0000-0002-0748-5085. Universitat Pompeu Fabra, España.xavier.ruiz@upf.edu

3 orcid.org/0000-0001-9468-7680. Universitat Pompeu Fabra, España. cristina.sanchezs@upf.edu 
a través de cambios de tipo cognitivo y emocional, y ejerciendo la solidaridad con sus allegados. Aquellos elementos potencialmente críticos con el neoliberalismo son desactivados al enlazarse con los discursos de las élites políticas y económicas.

\section{Palabras clave (fuente: tesauro de la Unesco)}

Publicidad; semiótica narrativa; semiología; crisis económica; recesión económica; nacionalismo; neoliberalismo; España. 


\section{Narratives of the Economic Crisis: National Neoliberalism in Spanish Advertising (2008-2017) ${ }^{1}$}

\section{Abstract}

Advertising, in addition to spreading discourses about products and brands, creates specific representations of society. Considering the economic crisis that Spain has been experiencing since 2008, this research aims to identify the narratives that have been produced about it in Spanish advertising between 2008 and 2017. Using a questionnaire administered to 45 advertising professionals in Spain, 31 spots that directly refer to the crisis have been identified. A qualitative content analysis inspired by narrative semiotics has been performed on these spots. Results show three dominant prototypical narratives that join together around two ideological trends: nationalism and neoliberalism. There are no story lines about the causes of the crisis or those responsible for it, while its solution is transferred to citizens, who must overcome it through cognitive and emotional changes and by being supportive with their kin. Those potentially critical elements of neoliberalism are neutralized by linking them with the discourses of political and economic elites.

\section{Keywords (source: Unesco Thesaurus)}

Advertising; narrative semiotics; semiology; economic crisis; economic recession; nationalism; neoliberalism; Spain.

1 This research derives from the project "Héroes de la crisis: narrativa y discurso social en la cultura popular contemporánea” (CSO2014-56830-P), funded by the Ministry of Economy and Competitiveness (Mineco) of the Government of Spain. 


\section{Narrativas da crise econômica: 0 neoliberalismo nacional na publicidade espanhola (2008-2017) ${ }^{1}$}

\section{Resumo}

A publicidade, além de difundir discursos sobre produtos e marcas, gera representações específicas da sociedade. Considerando a crise econômica que a Espanha sofre desde 2008, esta pesquisa tem como objetivo identificar quais são as narrativas que foram desenvolvidas na publicidade espanhola sobre essa crise, entre 2008 e 2017. Através de um questionário feito com 45 profissionais do setor publicitário na Espanha, foram identificadas 31 pontos que fazem referência direta à crise. Esses pontos foram analisados através de uma análise de conteúdo qualitativa inspirada na semiótica narrativa. Os resultados mostram três narrativas prototípicas dominantes articuladas em torno de dois eixos ideológicos: nacionalismo e neoliberalismo. Não há linhas de argumentação sobre as causas da crise ou seus responsáveis, além disso, a solução é transferida para os cidadãos, que devem sair da crise por meio de mudanças cognitivas e emocionais e exercer solidariedade com as pessoas mais próximas. Esses elementos potencialmente críticos do neoliberalismo são desativados pela ligação com os discursos das elites políticas e econômicas.

\section{Palavras-chave (fonte: tesauro da Unesco)}

Publicidade; semiótica narrativa; semiologia; crise econômica; recessão econômica; nacionalismo; neoliberalismo; Espanha.

1 Esta pesquisa surge no âmbito do projeto "Heróis da crise: narrativa e discurso social na cultura popular contemporânea” (CSO2014-56830-P), financiado pelo Ministério da Economia e Competitividade (Mineco) do Governo da Espanha. 


\section{Introducción}

Desde la cultura audiovisual popular, se pueden ver representadas distintas tensiones sociopolíticas y ansiedades sociales características del contexto y de la época. Tal y como establecen Lee, Chung \& Paik (2011), la publicidad es una institución con gran influencia a la hora de construir estándares humanos, creencias, actitudes y valores sociales, por lo que en ella se reproducen y reafirman determinadas conductas y representaciones de la realidad. Además, si el fin de la publicidad es "activar en el destinatario los mecanismos de identificación y pertenencia, por un lado, y al mismo tiempo servir de catalizador de las emociones, aspiraciones y deseos de la sociedad" (Castelló-Martínez, Ramos-Soler y Pino Romero, 2013, p. 662), estas determinadas conductas y representaciones de la realidad participan de una sociedad y de una cultura específicas: la sociedad y cultura de consumo. La publicidad refleja, modela y refuerza tan solo aquellos valores y estilos de vida que sirven a los intereses del sistema socioeconómico (Méndizy Domínguez, 1996; Pollay, 1986; Pollay \& Gallagher, 1990), fenómeno que Richard W. Pollay ha enmarcado dentro de la teoría del "espejo distorsionado". Así pues, el relato publicitario es "un discurso hegemónico, portador de ideología, al servicio de los intereses comerciales y, por tanto, determinado y determinante por y para el sistema” (García, 2015, p. 16). Teniendo en cuenta la actual situación de recesión económica que se inició en 2008 en España, la publicidad ha estado transmitiendo mensajes y valores acerca de la crisis y de cómo hacerle frente (Ahn, Song \& Sung, 2011; Castelló-Martínez et al., 2013).

El presente trabajo tiene como principal objetivo identificar qué tipo de narraciones sobre la crisis económica se han construido desde la publicidad española reciente. A continuación, se exponen aquellas investigaciones previas que analizan cómo desde la publicidad hay marcas que se valen de la propia crisis para promocionar un producto o servicio tanto a nivel internacional como a nivel nacional. Luego, se exponen la muestra y metodología empleadas y, finalmente, se presentan las narraciones prototípicas sobre la crisis identificadas tras el análisis del corpus. 


\section{Publicidad y crisis}

Más allá del análisis de los efectos de la crisis sobre las estrategias publicitarias y de marketing, como los identificados en las empresas de finanzas y servicios financieros estadounidenses (Ahn, Song \& Sung, 2011; Lee, Chung \& Taylor, 2011; Lee, Chung \& Paik, 2011; Lee, Taylor \& Chung, 2011) o en la industria alimentaria griega (Notta \& Vlachvei, 2015), la presente investigación se centra en aquellos análisis que exploran el significado cultural de la crisis.

Banet-Weiser (2013) analiza la construcción de la crisis económica de 2008 en los Estados Unidos a través de la publicidad de dos marcas: Chrysler y Levi's. A través de narrativas recuperadoras y nostálgicas, las marcas presentan la crisis como un obstáculo que los individuos pertenecientes a la clase obrera norteamericana deben superar como obligación moral y nacional. Además, en estas publicidades, se usa una retórica neoliberal sobre la esperanza, la meritocracia, las nuevas fronteras y el deber de las personas de cuidarse a sí mismas, por lo que estas historias no cuestionan la estructura económica. Son narrativas acerca de cómo los ciudadanos deben superar la crisis, en las que se habla de la recesión en términos abstractos, sin culpar a ninguna entidad.

También aparecen componentes relacionados con el nacionalismo y el patriotismo. La crisis es una oportunidad para la americanidad, para que las personas rescaten su nación de sus problemas. Por consiguiente, se construye una imagen de marca para la crisis en los Estados Unidos, donde esta es un problema, pero también, como consecuencia del individualismo emprendedor, es una oportunidad para que los estadounidenses cumplan con su destino: "arreglar las cosas" (Banet-Weiser, 2013, p. 173). La crisis económica es la oportunidad para volver a reconstruir, reescribir la mitología histórica norteamericana del emprendedor individual, del duro esfuerzo, de la ética del trabajo y de las fronteras abiertas.

En el caso español, hay que tener en cuenta las circunstancias que han llevado al país a un colapso económico, así como es necesario contem- 
plar las particularidades de la cultura española en cuanto a la crisis. Por un lado, y tal y como establecen Rodríguez Serrano, Gil-Soldevilla y Marzal (2015), en el contexto español el surgimiento de la crisis económica tuvo lugar al hilo de la llamada burbuja inmobiliaria, y esto, sumado a temas como la corrupción o la especulación, ha hecho que una parte importante de las producciones audiovisuales españolas recojan las angustias relacionadas con temas como la destrucción del espacio habitable y la quiebra de las certezas y de las seguridades. Los mismos autores analizan cuatro cortos creados dentro de la campaña Cinergía de Gas Natural Fenosa. Todos ellos muestran la fragilidad del espacio habitable frente al mundo exterior, poniendo en imagen la sensación de indefensión a través de recursos habituales del género cinematográfico del terror. Esta representación en concreto del espacio habitable sirve como metáfora de la crisis económica y como un modo de canalizar la angustia que la crisis de la vivienda provoca en los españoles.

Por otro lado, Alonso, Fernández e Ibáñez (2011), a través de grupos de discusión con ciudadanos españoles, identifican cómo a nivel social hay unos discursos dominantes sobre la crisis económica que influyen de manera sustancial en el consumo. Los españoles generan discursos de crítica al consumismo y de contención del gasto que se relacionan con un clima general de miedo en el empleo, lo que contribuye a no cuestionar las diferencias sociales y a racionalizar la estructura y el orden social. También se identifica un resurgimiento de la austeridad obrera en el colectivo con menos poder adquisitivo y aparecen discursos de resistencia frente al sistema, aunque ningún grupo es capaz de plantear límites a las prácticas de consumo actual. La clase media emergente es percibida por las clases más altas como la causante de la crisis, ya que su descontrol e irracionalidad han desequilibrado el sistema, y asíla ha colocado en una suerte de inferioridad moral. Así pues, la idea de exceso sustituye la idea de progreso para hacer referencia a los años previos a la crisis. Aparecen en este contexto discursos de culpabilidad, de que los españoles "han vivido por encima de sus posibilidades", participando en una sociedad de riqueza irreal, por lo que todos son responsables de la caída. El Estado aparece en estos discursos como un obstáculo para los españoles emprendedores y autónomos, un límite para su libertad individual. 
Esto se relaciona con que en los discursos de los ciudadanos también aparece una representación acomplejada de la singularidad de lo español. Se construye una imagen de la sociedad marcada por las pasiones y el descontrol, como si la naturaleza española tendiese a los excesos si no se aplican los mecanismos de represión adecuados. De hecho, respecto de Europa, España tiene una condición infantilizada, esperpéntica y surrealista, se trata de un país en eterno retraso y lleno de políticos corruptos.

Estos ejes discursivos identificados por Alonso et al. (2011) aparecen indirectamente en varios mensajes y estrategias publicitarias en España. Por ejemplo, respecto de la contención del gasto, Castelló-Martínez et al. (2013), Fernández, Alameda y Martín (2011) y Torres-Romay (2010a, $2010 b, 2011)$ identifican un auge de estrategias promocionales y de fidelización de marcas basadas en el precio y en la calidad, respectivamente. También se sustituyen aquellos valores que apelan a tendencias egocéntricas y utilitaristas por otros de carácter posmaterialista, como temas relacionados con el altruismo y el sentimiento de pertenencia, al igual que valores de carácter transitivo y colectivo, como la comprensión, la seguridad o la confianza, y valores individuales, como el afán de superación, la positividad o la autoestima (Castelló-Martínez et al., 2013; Martínez y Raya-González, 2014, 2015; Raya, 2017; Rodrigo y Rodrigo, 2013). Estos últimos valores se podrían interpretar como reacción a los discursos de culpabilidad mencionados.

Castelló-Martínez et al. (2013) concluyen que los mensajes publicitarios españoles en tiempos de crisis se podrían resumir con un "no hay mejor forma de hacer que las cosas cambien que cambiar nosotros mismos nuestra forma de ver las cosas", lo que enlazaría con la ausencia de discursos sociales que propongan alternativas económicas a la sociedad de consumo.

Respecto de la representación acomplejada de la singularidad de lo español, hay algunas empresas que apelan al sentimiento nacional o patriótico para recuperar la confianza de su público, como una campaña realizada por el Banco Santander y analizada por Cabezuelo-Lorenzo 
(2014). Para recuperar la confianza de los españoles en los poderes económicos, el Banco Santander resalta aspectos positivos de la sociedad española y estimula la fraternidad entre ciudadanos. En esta campaña, los españoles son un pueblo que necesita unirse para salir de la crisis y, además, ya han demostrado de qué son capaces en un pasado (sentimiento patrio, de identidad nacional).

Para acabar, Torres-Romay también identifica una nueva línea creativa surgida a causa de la crisis: la denominada advertcrisis (2010a, $2010 b, 2011)$, que parte de la hipótesis de que en la actividad creativa publicitaria se están reflejando nuevos roles sociales y nuevos contextos de relación que representan la crisis. Es decir, que hay una línea creativa que se caracteriza por valerse de la crisis para promocionar un producto o servicio. La investigación aquí presentada parte de esta línea presentada por esta autora.

\section{Objetivos y metodología}

El objetivo principal es identificar cuáles son las narraciones prototípicas propuestas por la industria publicitaria española en torno a un contexto social marcado por la recesión económica en el periodo de 2008 a 2017. Definimos aquí una narración prototípica como "un esquema o frame narrativo constituido a partir de las características comunes de un conjunto de narraciones que, bajo ciertos criterios y en niveles específicos de su configuración, aparecen como semejantes y conforman un conjunto homogéneo" (Ruiz Collantes, 2009a, p. 299).

Esta investigación se centra en el estudio de los spots publicitarios emitidos en televisión, ya que es el medio con mayor penetración en España (Asociación para la Investigación de Medios de Comunicación [AIMC], 2018) y el que recibe mayor inversión publicitaria (Sánchez , 2017). Además, al combinar varios recursos audiovisuales, la televisión tiene una carga visual y emocional que hace que los spots sean un vehículo eficaz para la transmisión de determinadas actitudes y estilos de vida (Castelló-Martínez et al., 2013), que pueden estar haciendo referencia a la crisis. 


\section{Muestra}

La técnica utilizada para identificar las campañas publicitarias analizadas ha sido un cuestionario realizado a 45 profesionales del sector publicitario en España. En este se les pedía indicar qué campañas emitidas en España desde 2008 recordaban que habían hecho referencia a la crisis económica. Para ello, los encuestados tenían tanto un espacio de respuesta libre (indicando marca y campaña) como un listado de marcas comerciales por elegir (algunas con campañas previamente identificadas que hacían referencia a la crisis, y otras no).

A partir de las respuestas de los encuestados, la muestra se ha limitado, exclusivamente, a aquellos anuncios de marcas comerciales en los que aparecen referencias explícitas a la crisis económica o a sus consecuencias, en línea con el concepto advertcrisis propuesto por Torres-Romay (2011). Asimismo, con el objetivo de explorar cómo se representa la realidad social española a través de la publicidad, se han obviado aquellos spots de campañas internacionales. Para homogeneizar la muestra, también se han descartado aquellas campañas institucionales y de organizaciones no gubernamentales.

Finalmente, nos encontramos con una muestra total de 31 spots, que se agrupan a continuación por marcas:

- Aquarius: Politicos extraordinarios I (2013), Politicos extraordinarios II (2013).

- Balay: Optimismo (2017).

- Campofrío: Cómicos en el cementerio (2011), El CV de todos (2012), Hazte extranjero (2013), Bombería (2014), Despertar (2015).

- Coca-Cola: Estás aquí para ser feliz (2009), Benditos bares (2013).

- Danone: Alimenta sonrisas (2013).

- El Almendro: Vuelve a casa por Navidad (2013).

- Freixenet: Brindis para que salga el sol (2010), Tu brindis (2012).

- Ikea: Donde caben dos caben tres (2009), No es más rico el que más tiene (2011), Testamento (2011), La otra Navidad (2014). 
- La Sirena: Este año se puede (2012).

- Lotería Navidad: El mayor premio es compartirlo (2014).

- Mahou: Celebra lo que tienes (2011), O todos o ninguno (2011).

- Marcilla: Ayúdanos a ayudar (2011), El aroma que nos une (2013), Alli donde estés (2016).

- Movistar: Resistiré (2009), Asamblea (2011), Porque no solo jugamos bien al fútbol (2013).

- Repsol: Lola (2012).

- Telefónica: Plan para parados I (2009), Plan para parados II (2009).

\section{Análisis de contenido}

La técnica utilizada para el análisis de estos spots ha sido el análisis de contenido cualitativo, en esta ocasión abordado desde un enfoque semiótico-narrativo (Courtés, 1997, 1980; Greimas, 1970), ya que, y de acuerdo con el objetivo principal de esta investigación, esta aproximación nos permite explicar las estructuras narrativas de los spots. Autores como Bassilua (2017), Floch (1991), Mangano \& Marrone (2015), Pineda, Pérez de Algaba Chicano y Hernández-Santaolalla (2013), Ruiz Collantes (2009b), Ruiz Collantes \& Oliva (2015), Ruiz Collantes et al. (2009), Sánchez (1991) y Shairi \& Tajbakhsh (2010), entre otros, han probado con anterioridad la utilidad de una aproximación semiótico-narrativa para el análisis de la publicidad. En esta ocasión, se ha creado una parrilla de análisis tomando como modelo aquella creada por Ruiz Collantes et al. (2008) para analizar ficción audiovisual.

La semiótica narrativa permite identificar la estructura básica de una narración, que en palabras de Courtés consiste en un cambio "entre dos estados sucesivos y diferentes (1997, p. 103), es decir, en una transformación de una posición inicial a una posición final.

La teoría de la semiótica narrativa presenta un modelo canónico de la narración, una serie de fases que van desde el contrato, en el que se establece cuál es la misión de los sujetos; la adquisición de competencias, que 
consiste en la obtención de motivos y capacidades para desarrollar la misión; la ejecución de la misión, hasta la fase de sanción, positiva o negativa respecto de la misión y de sus resultados. A estas cuatro fases estándar se ha añadido una previa a todas ellas y que aquí se ha denominado fase de desajuste. Esta fase remite a una situación previa en la que se produce algún tipo de perturbación que genera el desarrollo narrativo posterior. Esta fase inicial aparece de diversas maneras en otros modelos narrativos. Por ejemplo, Propp (1971) explica el cuento maravilloso en función de una carencia que debe liquidarse, y Todorov (1966) establece que la estructura de una narración parte de una situación que entra en desequilibrio, lo que genera la búsqueda de un nuevo equilibrio. De hecho, desde el análisis semiótico-narrativo publicitario, también se ha hecho mención de una "carencia inicial" estrechamente relacionada con las necesidades de consumo (Sánchez , 1991). En esta ocasión, se ha procedido a considerar esta fase adicional porque su análisis aporta información relevante acerca de cómo se describen las posibles causas de la crisis.

Según la semiótica narrativa greimasiana, las unidades básicas del modelo de análisis de las estructuras narrativas son los actantes, que pueden concebirse como todos aquellos seres o cosas que realizan o sufren el acto dentro de un proceso narrativo (Greimas y Courtés, 1982). Estos actantes se pueden articular alrededor de tres ejes fundamentales (Greimas, 1971): sujeto/objeto, destinador/destinatario y adyuvante/oponente. En este estudio, se han redefinido los actantes para adaptarlos al objetivo del análisis y se les ha dado otra denominación para hacer más simple la comprensión de su sentido. Según las fases de la narración, los actantes serán:

- Desajuste: Agente de desajuste: sujeto responsable del desajuste. Sujeto desajustado: personaje que padece el desajuste.

- Contrato: Proponente de contrato o misión: personaje que encarga una misión. Destinatario de contrato o misión: sujeto que recibe el encargo de realizar una misión.

- Competencias: Motivaciones: querer y deber. Capacidades: saber y poder. 
- Ejecución: Agente de la misión o héroe: personaje que desarrolla la misión. Contrincante: adversario del héroe. Beneficiario: personaje en favor del cual se realiza la misión. Adyuvante: personaje que facilita la misión. Oponente: personaje que dificulta la misión. Objetivo: resultado a alcanzar con la misión.

- Sanción: Sancionador: sujeto que premia o castiga al agente de la misión según si ha cumplido o no su compromiso. Sancionado: el agente de la misión en tanto que premiado o castigado.

Por otro lado, y con el objetivo de relacionar estas narraciones con un contexto social marcado por la crisis económica, se han analizado ítems relacionados con el mundo ficcional, concepto extraído de Dolezel (1998) que hace referencia a que, al narrar, se simula un mundo determinado dentro de un conjunto de mundos ficcionales múltiples y posibles. Es posible que se establezca una relación intermundo entre narración y realidad, y es en este punto en el que se buscan las correspondencias entre el contexto de recesión económica español y las historias en las que la crisis aparece explícitamente.

Esta apreciación se relacionaría con lo que en la narratología contemporánea se denominan metanarrativas, que Dolezel (1998) llama digresiones representativas, y que son partes del discurso que están dentro del texto ficcional, pero que expresan opiniones (creencias) sobre el mundo real.

Las categorías que se han tenido en cuenta para el análisis del mundo ficcional se han extraído a partir de los análisis de la representación de la crisis económica en la cultura mediática popular realizados por Boyle \& Mrozowski (2013), Kellner (2011) y Ryan \& Kellner (1988). Estos ítems son el contexto espacio-temporal descrito, las características del mundo ficcional, la presencia y la descripción de un conflicto y las líneas argumentales específicas sobre este (causas, consecuencias, soluciones y valores implicados).

\section{Resultados}

A continuación, se presentan las narrativas prototípicas identificadas en el análisis. Aparte de la referencia a los spots de los que se ha extraído cada 
narrativa, al principio de cada apartado se añade un resumen de un spot característico de la muestra para facilitar la comprensión de los resultados.

\section{Narrativa 1: Españoles, arriba el ánimo}

Un total de 9 anuncios de 31:

- Campofrío: Cómicos en el cementerio (2011), El CV de todos (2012), Hazte extranjero (2013).

- Movistar: Resistiré (2009), Porque no solo jugamos bien al fútbol (2013).

- $\quad$ Freixenet: Brindis para que salga el sol (2010).

- Mahou: Celebra lo que tienes (2011).

- Aquarius: Políticos extraordinarios I (2013), Políticos extraordinarios II (2013).

Resumen Campofrío:

Hazte extranjero (2013): dicen que España ocupa las últimas posiciones en casi todos los rankings, por lo que se inicia una campaña para que los españoles adopten otra nacionalidad y así puedan estar orgullosos de su identidad. Sin embargo, tras realizar este cambio, los españoles ven que no encajan en la idiosincrasia de otras nacionalidades (“ $i$ Pero qué hacemos con eso de abrazarnos y tocarnos todo el rato? ¿Y el sentido del humor, qué hacemos con él?”). Al final, se concluye que los españoles tienen un carácter al que no pueden renunciar porque es su naturaleza: "Uno puede irse, pero no hacerse", "Que nada ni nadie nos quite nuestra manera de disfrutar de la vida”.

Descripción de la narrativa:

1. Desajuste: como consecuencia de la crisis económica, aparecen españoles con la autoestima baja, que se creen incompetentes o están tan deprimidos que no saben cómo salir adelante. Por consiguiente, la mayor parte de los problemas que se presentan son del tipo cognitivo y emocional. 
En la mayoría de las ocasiones, los sujetos desajustados son los españoles en su conjunto, que se representan a través de distintos personajes y que son los que se autoplantean la misión de levantar el ánimo. Por ello, los personajes funcionan como representantes de los españoles y como representantes de las marcas que apelan a los españoles para que alcancen un estado emocional más positivo.

La referencia a la crisis como agente del desajuste que genera tensión y desencadena la narración es sutil o metafórica y, en general, no se menciona directamente, por lo que la crisis como causa de los estados emocionales negativos en los españoles se da por presupuesta.

2. Contrato: normalmente, las marcas son el proponente de la misión, es decir, que proponen el desarrollo de una misión a los españoles, que funcionan como destinatarios del contrato propuesto. La misión consiste en levantar el ánimo y la autoestima para lograr un estado emocional más positivo y salir de la postración depresiva en la que los españoles se encuentran.

La manipulación contractual, es decir, la manera en que se incita a los destinatarios a aceptar y desarrollar la misión, es de tres tipos:

a. La amenaza, en que se indica a los españoles que seguir con un estado de abatimiento llevará a consecuencias negativas.

b. La promesa, en que se les sugiere que tener un tono emocional más positivo les hará obtener una vida más gratificante.

c. La seducción, en que se incita a los españoles a cambiar su estado emocional aduciendo que tienen un sentido del humor y personalidad únicos y han alcanzado grandes logros en la cultura, el deporte y la ciencia, y así alimentar su autoestima y el orgullo de ser españoles. En algunos spots, se compara a los españoles con personas de otras nacionalidades para poner en primer plano que estas no poseen las cualidades que sí tienen las personas de nacionalidad española. 
3. Competencias: las capacidades que "los españoles", como héroe colectivo de la misión planteada, deben alcanzar para el éxito de su cometido, son innatas, ya que se apela al carácter nacional como el elemento clave para superar un estado de ánimo negativo.

4. Ejecución: los objetivos que aparecen en estas narraciones están relacionados, en el mayor número de casos, con levantar el ánimo. En segundo lugar, también se presenta el objetivo de resistir, que se plantea al sujeto colectivo "españoles" de dos maneras: aguantar hasta que la crisis acabe y seguir manteniendo las características de su carácter nacional. Así pues, la misión que se encomienda a los españoles es seguir siendo tan españoles como hasta ese momento, lo que implica que no hay que cambiar ni mejorar.

La acción esencial que los españoles deben realizar para alcanzar el objeto de valor es modificar el punto de vista acerca de las cosas y recordar y tener en cuenta las cualidades positivas de los españoles. Solo hay unos pocos casos excepcionales en los que la acción pasa por esperar/resistir, y así se entiende que lo que ocurre (la crisis) es cíclico y que en algún momento acabará, aunque no se explicita cuándo.

En todos los casos el héroe de la misión y del relato son los españoles, ya sea en general, ya sea representados a través de determinados personajes tanto anónimos como celebridades. En esta narrativa prototípica, no se determinan las causas de la crisis económica, pero se responsabiliza a los ciudadanos españoles de la solución a su situación depresiva que es consecuencia de dicha crisis.

En algunos de los spots que se incluyen en la presente narrativa prototípica, aparecen contrincantes frente a los que hay que actuar para tener éxito en la misión. En primer lugar, a veces aparece un marco competitivo implícito entre españoles y personajes de otras nacionalidades, en el que se alude a que los individuos españoles son los primeros del mundo o de Europa en su ámbito de actuación profesional. En segundo lugar, en algunos spots aparece la tendencia de los españoles a dejar de ser españoles para convertirse en personas de otras na- 
cionalidades, en especial del centro y norte de Europa. En este caso, son los propios españoles que admiran los modelos de otras nacionalidades europeas los que se convierten en contrincantes dentro de la misión. Aparece entonces una contradicción interna: los españoles, para conseguir el objetivo de seguir siendo españoles, deben luchar contra sus propias inclinaciones por cambiar y ser como las personas de otras nacionalidades. En síntesis, se pone en confrontación lo español frente a "lo extranjero" y se privilegia el eje nosotros-ellos.

En la narrativa, aparecen factores de diferente tipo que funcionan como oponentes. En la mayor parte de los casos, son circunstanciales pero también emocionales: el pesimismo contagiado, una sensación general de que las cosas van mal, el olvido de la identidad española, la negatividad, la depresión, etc. Por otro lado, también aparecen otros oponentes que se relacionarían directamente con los efectos de la crisis, como la bajada del Dow Jones, los bancos que no avalan con nuevos préstamos, las cifras del desempleo, o la salida a la luz de graves casos de corrupción .

Los adyuvantes son diversos. En bastantes spots, son las marcas que dan la información y productos a los españoles para que levanten el ánimo y resistan. En menor medida, encontramos spots en los que los adyuvantes son la autoconfianza y el recuerdo de las muchas cosas positivas que los españoles hicieron en el pasado, que se relacionaría con la toma de conciencia de la identidad española, la reivindicación del "auténticamente nosotros" respecto de un "otro" que no siempre se define.

En la mayor parte de casos, la esfera de actuación de los españoles, en el desarrollo de su misión, es privada, tanto individual como colectiva. Se desarrolla en el ámbito personal o profesional, y nunca en el de las políticas públicas.

El éxito de la misión aparece en algunos spots en los que se presentan imágenes en las que los personajes que representan a la totalidad de los españoles tienen un estado de ánimo positivo. 
5. Sanción: cuando en los spots aparecen personajes que representan al colectivo "españoles" y que se proponen ellos mismos la misión, entonces se explicita un final exitoso y son los mismos personajes los que se reconocen a sí mismos como colectivo que ha sido capaz de cumplir con los objetivos que se había planteado.

6. Mundo ficcional: en cuanto al contexto espacio-temporal en el que se desarrollan las historias, nos encontramos con que la mayoría de ellas suceden en la actualidad respecto del momento de emisión de los anuncios. Los espacios suelen ser variados, públicos y exteriores. Hay algunas marcas que optan por una estética retro tanto en la imagen (filtros sepia o similares) como en la ambientación (tecnología anticuada, como teléfonos, televisores o transporte). Este recurso refuerza la acción cognitiva de hacer referencia a un pasado positivo para levantar el ánimo.

\section{Narrativa 2: Somos así de solidarios}

Un total de 12 anuncios de 31:

- Campofrío: Bombería (2014).

- El Almendro: Vuelve a casa por Navidad (2016).

- Ikea: Donde caben dos caben tres (2009).

- Coca-Cola: Benditos bares (2013).

- Mahou: O todos o ninguno (2011).

- Balay: Optimismo (2017).

- Marcilla: Ayúdanos a ayudar (2011), El aroma que nos une (2013), Allí donde estés (2016).

- $\quad$ Telefónica: Plan para parados I (2009), Plan para parados II (2009).

- Lotería Navidad: El mayor premio es compartirlo (2014).

Resumen Lotería Navidad:

El mayor premio es compartirlo (2014): Antonio, dueño de un bar, le pregunta a Manuel, cliente de confianza, si quiere comprar lotería. Este de- 
clina la oferta porque no tiene dinero suficiente, pues está en paro, y además ha perdido la ilusión. Antonio le dice que no pierda la ilusión y, una vez Manuel se marcha, coge un boleto y lo mete en un sobre. El día del sorteo, el Gordo de Navidad cae en el bar de Antonio. Manuel, arrepentido por no haberle comprado lotería, va al bar a felicitarlo y cuando va a pagar el café que se ha tomado, Antonio le pide $21 €, 1 €$ del café y $20 €$ del boleto que le había guardado, que resulta ser el ganador.

Descripción de la narrativa:

1. Desajuste: en esta narrativa, nos encontramos con que el desajuste que produce la crisis económica en los personajes está relacionado con el empleo: cierran las empresas y los trabajadores se quedan en paro; muchos jóvenes tienen que emigrar al extranjero a trabajar; un joven está trabajando en otro continente y no puede estar con su familia en Navidad; un joven se queda sin trabajo y no puede salir a tomarse unas cervezas con sus amigos; los jóvenes tienen que volver a casa de sus padres al no tener recursos para tener una vida autónoma; las familias pasan por dificultades graves para poder obtener bienes básicos, etc. Como puede observarse, el trabajo aparece de dos maneras, y las dos en clave negativa: o los españoles pierden el empleo o se tienen que marchar al extranjero a trabajar. En ambos casos, esto les genera carencias y malestar en su vida personal, pero no se produce un discurso sobre por qué los españoles están sin empleo.

Los sujetos desajustados, los que sufren una privación o un problema como consecuencia del desempleo, son todos españoles y hay una cantidad considerable de spots en los que aparecen los jóvenes como protagonistas. Los jóvenes son el gran núcleo del precariado en España actualmente tras las reformas laborales aplicadas en contexto de crisis. Otro perfil de precariado laboral son los mayores de 50 años, que también aparecen en estas historias pero en menor medida.

2. Contrato: el proponente de la misión pueden ser las marcas o los españoles en función de cuál sea el rol de la marca en la campaña. Si se trata de una campaña en la que la marca expone su responsabilidad 
social corporativa (RSC), entonces el proponente de la misión será esta. Si simplemente se exponen historias de solidaridad, el proponente son españoles anónimos o las marcas representadas a través de ellos. Relacionado con esto, por norma general, el destinatario del contrato para que desarrolle la misión propuesta son los españoles $y$, normalmente, se representan a través de familias, grupos de amigos, colegas, o compañeros.

La manipulación contractual se mueve entre la amenaza, pues se alude a que hay allegados de los españoles que lo están pasando mal, y la promesa, ya que se argumenta que los españoles han de estar unidos y ayudar a sus allegados porque así serán todos más felices. La promesa, a veces, tiene un carácter de seducción, ya que la solidaridad se presenta como una faceta de la personalidad de los españoles que los hace especiales.

3. Competencias: los españoles se presentan como naturalmente solidarios, por lo que son totalmente competentes para desarrollar la misión que se les encomienda. En alguna ocasión puntual, también nos encontramos con que determinados españoles quieren ser solidarios pero no pueden por no disponer de los suficientes medios. En estos casos, son las marcas las que les transfieren la competencia del poder a través de los recursos que les son necesarios para ejercer la solidaridad.

4. Ejecución: Los objetivos en este tipo de narrativa están relacionados con las metas de estar unidos, evitar el sufrimiento ajeno y seguir siendo españoles, porque ser solidarios unos con otros es una forma de mantener el carácter nacional. Para ello, es necesario que la acción pase por la ayuda de unos hacia otros: consumiendo productos de marcas solidarias, adquiriendo productos que facilitan la tarea de ser solidario, ayudando económicamente a los seres queridos, etc. En general, la solidaridad pasa por el consumo y la economía.

El agente de la misión suelen ser ciudadanos españoles que actúan de manera individual o colectiva en tanto familias, grupos de ami- 
gos, compañeros de trabajo, etc. También, en algunos casos, aparecen como héroes las marcas cuando desarrollan campañas de RSC.

El beneficiario de la misión son siempre los españoles: los allegados de los solidarios o bien un sujeto abstracto con una fuerte carga simbólica en la cultura española, como los bares, que están pasando por serias dificultades.

En general, no aparecen personajes que ejercen el rol narrativo de adyuvante. En algunas ocasiones, este papel lo desempeñan las propias marcas o algún personaje español que ayuda a otro español para que pueda ejercer la solidaridad. El oponente a veces es simplemente el azar y la mala suerte $y$, otras, aspectos circunstanciales, como la falta de espacio en el hogar, la falta de dinero, la avanzada edad, etc. En esta narración prototípica, no aparecen personajes en el rol de contrincantes.

La esfera de actuación es siempre privada, es decir, o se da una solidaridad entre allegados o se ayuda a individuos concretos. La actuación de los personajes nunca implica una solidaridad entre distintos grupos de la sociedad más o menos alejados por características sociales, económicas, nacionales o étnicas, ni se hace una llamada, por ejemplo, a que las instituciones públicas y políticas asistan a los ciudadanos que lo necesiten. De esta manera, se apoya la idea de que la solidaridad individual y ejercida de manera privada es el modo más natural, adecuado o justo, para aligerar los efectos de la crisis económica en aquellos sujetos que más los sufren.

En general, a los sujetos solidarios no les supone ninguna dificultad socorrer a sus allegados, pues tienen los medios necesarios para ello sin que esto ponga en peligro su bienestar o su forma de vida. Por otro lado, en los diferentes relatos que corresponden a esta narración prototípica, la misión siempre resulta exitosa, es decir, los españoles y las marcas son solidarios y contribuyen a reducir el sufrimiento de sus allegados o de sus compatriotas. 
5. Sanción: en la mayor parte de las historias de esta narración prototípica, los individuos que reciben la solidaridad sancionan positivamente a los sujetos que son solidarios con ellos. Esta sanción aparece representada a través de celebraciones familiares o entre amigos y de muestras de agradecimiento.

6. Mundo ficcional: en cuanto al contexto espacio-temporal, todas las historias suceden en el mundo de la actualidad, presente respecto del tiempo de las emisiones de los spots. Hay algunos tipos de espacios en los que se desarrollan las acciones y que se repiten en varios spots: hogares familiares, ciudades en el extranjero, fábricas, talleres u oficinas y bares. También aparecen otros espacios variados, como hospitales, metros, restaurantes, coches, etc.

\section{Narrativa 3: Vive feliz con lo que tienes}

Un total de 9 anuncios de 31:

- Campofrío: Despertar (2015).

- Repsol: Lola (2012).

- Ikea: No es más rico (2011), Testamento (2011), La otra Navidad (2014).

- Coca-Cola: Estás aquí para ser feliz (2009).

- $\quad$ Freixenet: Tu brindis (2012).

- La Sirena: Este año se puede (2012).

- Danone: Alimenta sonrisas (2013).

Resumen Ikea:

No es más rico (2011): aparecen imágenes de distintos hogares donde parejas, amigos y familias disfrutan de situaciones cotidianas, sencillas y de tono austero: juegan, cocinan, comen, leen, se toman un baño o se relajan, ven la televisión o riegan las plantas, entre otras cosas. En contraposición, de fondo suena una canción de cantautor en la que se enumeran bienes materiales con un carácter de lujo y ostentación: "Business, High class, $120 \mathrm{cv}$, [...], dúplex, tríplex, loft, 21 pulgadas, 46 pulgadas, 80 pulgadas, [... ], pla- 
ta, oro, platino, socio, socio abonado, socio VIP, anti-age, botox, ácido hialurónico, $[\ldots]$, special full $\mathrm{HD}$ ”, que concluye con "No es más rico el que más tiene, sino el que menos necesita”.

Descripción de la narrativa:

1. Desajuste: el estado que desencadena las actitudes y acciones de los personajes es la crisis económica, que no se presenta solo como un problema sino también como una oportunidad. Se hace referencia, de forma explícita o implícita, a un entorno económico y social que ha cambiado y, como consecuencia, los españoles han de adaptarse. El problema para la adaptación a la nueva situación es la cultura consumista de los destinatarios de los mensajes. Por ello, el agente del desajuste es la contradicción que se produce entre la llegada de una crisis económica y la cultura consumista de los ciudadanos.

Normalmente, aparecen como sujetos desajustados, personas anónimas que representan a los españoles en su conjunto y que se encuentran en un entorno socioeconómico nuevo que los obliga a cambiar, en algún sentido, su forma de vida. Es interesante destacar que todos los personajes que aparecen en los spots ya saben cómo afrontar la nueva situación de crisis económica, por lo que la descripción de la situación de desajuste es mínima y en general implícita. Las historias comienzan cuando los protagonistas han asumido la misión de cambiar sus valores y sus hábitos, y adaptarse al nuevo estilo de vida que la crisis económica impone.

2. Contrato: el proponente de la misión son las marcas a través de distintos personajes que aparecen en los spots. Los destinatarios del contrato para desarrollar la misión pueden ser algunos personajes anónimos que aparecen en los spots o bien los consumidores en su conjunto y sin especificar.

La misión que se propone es de carácter cognitivo, emocional y conductual. Se trata de un discurso de adaptación a la crisis económica, de 
afrontar la vida de otra manera, lejos del espíritu consumista anterior, y valorar aquello que es realmente fundamental y valioso. Se incita a que se dejen de lado valores como la abundancia de bienes, la ostentación y el lujo, y a que las personas se centren en dar la máxima importancia a las cosas más sencillas de la vida cotidiana y, en especial, a la compañía y el cariño de los familiares, los amigos y los compañeros.

El tipo de manipulación contractual es en general la promesa, ya que nos encontramos con mensajes en clave positiva que instan a los consumidores a disfrutar de lo realmente importante en la vida y ser así auténticamente felices.

3. Competencias: en los spots se presupone que los consumidores quieren y pueden llevar a cabo la misión que se les propone (seguir siendo felices en un contexto de crisis económica), pero no saben cómo hacerlo. Por ello, las marcas, a través de voces en off o de personajes anónimos, transfieren a los consumidores el saber que les hace falta: para ser felices y disfrutar de la vida deben atender menos a los grandes bienes materiales y centrarse en las pequeñas cosas de la vida cotidiana y en las relaciones afectivas con sus personas más próximas.

4. Ejecución: en los spots, el objetivo propuesto aparece ya conseguido. Las personas que desarrollan su misión aparecen en situaciones de disfrute y felicidad: mirando una puesta de sol, recreándose en unos minutos más en la cama, abrazando a su hija, compartiendo una animada celebración alrededor de una mesa con la familia, etc. De esta manera, los individuos muestran cómo desarrollan su misión y alcanzan momentos de dicha en un contexto de crisis social.

Los héroes son siempre personajes que representan sujetos de clase media, hombres y mujeres y de todas las edades, y en roles propios de la vida cotidiana, en especial de carácter familiar. La esfera de actuación es siempre privada. Los beneficiarios de la misión son los mismos héroes, lo que implica que esta filosofía de vida que se propone en los spots es totalmente individualista, es una decisión que se toma 
a escala personal para provecho propio y que como mucho influye positivamente en los círculos más cercanos dentro de la esfera de la vida privada.

No aparece ningún personaje que asuma el rol de contrincante, que impida que los consumidores alcancen la felicidad. No se generan incompatibilidades ni conflictos y así, todos, si aprenden a vivir intensamente las cosas simples que son en realidad importantes, alcanzan la dicha y disfrutan de la vida.

En general, los adyuvantes son las marcas, que son las que ofrecen la información necesaria a los españoles para aprender a vivir con menos y disfrutar más de los bienes no materiales que te ofrece la vida. Por otro lado, hay spots que presentan como adyuvantes todas aquellas cosas bonitas de la vida que hacen que sea más fácil disfrutar de ella, como el amor, el hogar, o la familia.

Los oponentes en esta narración son variados: puede ser el pesimismo, la cultura consumista, consecuencias de la crisis que resultan graves y son difíciles de superar, etc. La misión siempre acaba con éxito y la fórmula de la felicidad que proponen las marcas se presenta como apropiada y acertada.

5. Sanción: no en todos los spots aparecen escenas de sanción, pero cuando aparece siempre es positiva. Los mismos consumidores se sancionan a sí mismos a través de gestos o actitudes que revelan que están satisfechos consigo mismos. También son sancionados positivamente por otras personas allegadas o por la propia marca.

6. Mundo ficcional: en cuanto al contexto espacio-temporal en el que se desarrollan las historias, en todos los casos se trata de un tiempo presente respecto del momento de la emisión de los spots y los espacios que aparecen son varios, pero, en general, se pueden dividir entre espacios exteriores de ciudades y pueblos e interiores de hogares. 


\section{Narrativa 4: El poder de la gente}

Un total de 1 anuncio de 31 :

Movistar: Asamblea (2011): en este caso, no se analiza una narrativa prototípica, sino solo la narrativa de un spot que no se incluye en ninguna de las narrativas prototípicas establecidas.

Resumen de Movistar y descripción de la narrativa:

Asamblea (2011):

1. Desajuste: los usuarios de telefonía móvil no están satisfechos con las prestaciones y precios de sus servicios.

2. Contrato: los usuarios en una asamblea deciden qué pedir a la compañía telefónica. Se establece un deber para la marca, puesto que se presupone que los usuarios tienen el derecho a pedir lo que deseen.

3. Competencias: la marca quiere y puede cumplir las demandas de sus clientes.

4. Ejecución: la marca se convierte en agente de la misión, puesto que se supone que ejecuta lo que sus clientes le han pedido. Los usuarios son los beneficiarios.

5. Sanción: positiva. Los usuarios celebran pedir lo que desean y que la marca lo cumpla.

6. Mundo ficcional: el universo ficcional remite a las asambleas del Movimiento $15 \mathrm{M}$ a través del cual parte de la ciudadanía en España protestó contra los responsables de la crisis y puso en duda el sistema económico y la representatividad democrática que ostentaban los políticos.

\section{Conclusiones}

El primer componente ideológico de los spots de la crisis en España tiene un carácter nacionalista. Según los spots que conforman la primera narrativa prototípica identificada, "Españoles, arriba el ánimo", la crisis económica 
se transforma en España en una grave crisis de autoconfianza y de autoestima de los españoles. Los spots los muestran deprimidos, acomplejados y sin confiar en sus competencias y posibilidades. Por ello, se hacen llamamientos constantes a que los españoles no olviden lo que son, aquello de lo que estaban orgullosos como comunidad nacional. Se habla de los españoles como gente preparada para prosperar y competir en el mundo presente, con sentido del humor y con costumbres que no solo no deben perder sino que deben preservar y defender a pesar de la crisis. Hay numerosas referencias a los logros de todo tipo que los españoles consiguieron en el pasado, presentándose la españolidad como una garantía para superar la crisis o para minimizar sus efectos negativos.

Esta narrativa nacionalista transforma la crisis económica en una crisis de identidad nacional que se debe resolver desde una autoafirmación identitaria de cada uno de los españoles. De este modo, la crisis económica y social pasa de lo público y social a lo privado e individual y de lo objetivo a lo subjetivo.

Las características positivas del carácter nacional español también se ponen de relieve comparándolas con otros caracteres de países extranjeros. Así se establece un marco competitivo que tiene su eje de referencia en el mercado global: los españoles se reivindican como sujetos preparados para competir con los ciudadanos de otras nacionalidades.

En los spots analizados, no hay una explicación de las causas de la crisis económica, no aparecen personajes responsables ni factores de carácter nacional que hayan llevado al fracaso: ni los políticos, ni las élites económicas, ni las organizaciones sindicales, etc. Tampoco existe ninguna cualidad del carácter nacional que haya que erradicar, aminorar, renovar u optimizar. Lo único que se presenta como negativo en los españoles son sus dudas respecto del valor eminentemente positivo de lo que han sido, de lo que son y de lo que deben seguir siendo.

Desde la perspectiva planteada, la crisis económica se muestra como algo puramente casual y circunstancial. Nadie ha sido responsable de su 
aparición y nadie será responsable de su desaparición, por tanto, lo único que se debe hacer es resistir y no cambiar. Según el discurso aquí analizado, la crisis no es responsabilidad de los españoles, lo que sí es responsabilidad de los españoles es seguir siendo españoles.

En algunos de los spots analizados, hay claras referencias a la solidaridad, de acuerdo con la narrativa prototípica "Somos así de solidarios". En estos spots, se apela a la ayuda que los ciudadanos se pueden dar unos a otros para hacer menos graves las consecuencias de la crisis económica y, por ello, se ponen en primer plano valores sociales positivos. En los spots, se muestran personas que sufren las consecuencias negativas de la crisis económica, fundamentalmente relacionadas con el desempleo. Todos los afectados por el desempleo — en su mayoría jóvenes — aparecen con carencias en su vida cotidiana tanto materiales como emocionales, que son minimizadas a través de la solidaridad de sus allegados. Según el discurso de los spots analizados, la solución al desempleo y las otras lacras que genera la crisis económica se da estrictamente a través de lo privado. Son las relaciones personales y de proximidad vivencial las que deben activar y activan la solidaridad entre personas. Los componentes y características de la estructura socioeconómica y del sistema político no aparecen como factores responsables en la eclosión de la crisis económica ni tampoco en su solución de sus efectos. Cuando se hace referencia al sistema de poder político del país, no se demandan soluciones, sino que se ponen en primer plano algunas actitudes solidarias de políticos individuales respecto de sus conciudadanos. Si alguien vive una situación de emergencia, solo debe esperar ayuda por parte de sus padres, hermanos, hijos, amigos, vecinos, compañeros en el taller o en la oficina. De este modo, la solidaridad es horizontal, entre iguales, y nunca se da entre personas de distintas clases y sectores sociales, etnias, orígenes, o nacionalidades. Esta solidaridad tampoco tiene la intención ni de transformar ni de cuestionar el sistema, ya que acepta el orden económico, social y político. Por otro lado, en algunos spots se pone de relieve cómo las marcas también asisten a los ciudadanos.

Lo que determina la ideología que hay detrás de un concepto de solidaridad son los sujetos implicados y los límites de dicha solidaridad. La solidaridad que se desarrolla solo de manera directa entre individuos próxi- 
mos o entre corporaciones empresariales y consumidores, todo ello dentro de un marco de relaciones privadas, tal como ocurre en las historias de los spots analizados, remite a una solidaridad de matriz ideológico- neoliberal. En los spots de la narrativa que aquí se señala, no aparece una apelación a la solidaridad entre sujetos de diferentes clases sociales, nacionalidades o culturas a través de tareas de redistribución de la riqueza por medio de políticas propias de los poderes públicos. Ello supondría romper los marcos mentales del neoliberalismo y entrar en el ámbito del discurso socialdemócrata, por ejemplo. Por otro lado, aparecen españoles ayudando a otros españoles que han emigrado al extranjero, pero en ningún spot se muestran españoles ayudando a personas inmigrantes de otras nacionalidades que han llegado a España, lo cual, en la cultura política europea, hace referencia a una barrera en el ejercicio de la solidaridad que alude a una posición propia de la derecha populista.

En los spots analizados, no se niegan o rechazan explícitamente otras formas de solidaridad que superen los límites impuestos por los modelos de solidaridad neoliberal o nacional-populista, simplemente estas otras formas de solidaridad más amplias y más estructurales no aparecen y, como consecuencia, se invisibilizan.

La tendencia a ser solidarios en varios de los spots se presenta como una cualidad típicamente española. De esta manera, la apelación a un tipo específico de solidaridad no solo contribuye a apuntalar un discurso neoliberal en los comportamientos ciudadanos frente a la crisis, sino que también consolida el discurso nacionalista.

Por otro lado, en algunos de los spots analizados, aquellos que fundamentan la narrativa "Vive feliz con lo que tienes", se transmite un discurso mediante el cual se invita a los ciudadanos a adaptarse a las nuevas situaciones de precariedad económica y de menor capacidad adquisitiva y de consumo. En general, este discurso se hace aludiendo directamente al hecho de que los valores más importantes en la vida no están relacionados con los bienes y servicios que se poseen, se usan y se consumen, sino con las cosas esenciales, como las relaciones con las personas queridas y las emociones agradables que procuran las situaciones más sencillas. 
La apelación a la reducción del gasto en el consumo y a huir del derroche y la ostentación podría ser entendida como propia de un discurso anticonsumista de tipo ecologista o anticapitalista. Sin embargo, hay que tener en cuenta que los spots que mantienen este tipo de mensajes corresponden a marcas low-cost que ponen de relieve el valor del ahorro y no sustentan su oferta en la ostentación del estatus social.

Por otro lado, aunque los contenidos de estos spots apoyan valores de una cultura alternativa respecto del consumo masivo, en el contexto español de la crisis, este discurso adquiere también un sentido muy específico. Una de las frases más repetidas a la población durante los años más duros de la crisis por parte de las élites políticas y económicas y de los medios de comunicación fue "habéis vivido por encima de vuestras posibilidades". Este discurso social trasladaba la culpa de la crisis a los ciudadanos por, supuestamente, haber derrochado recursos en un nivel de vida que realmente no les correspondía. En ese contexto, la apelación de la publicidad a la austeridad y a poner en valor las cosas sencillas de la vida, lo que hacía era abundar en el discurso de la culpabilización de los ciudadanos por un pecado que tenían que pagar a través de una vida humilde y frugal que, además, debían ver como positiva.

Así pues, ante una situación en la que el sistema socioeconómico se degrada y pone en dificultades a los ciudadanos, no es el sistema socioeconómico el que debe cambiar sus reglas, sino que son los ciudadanos los que se deben adaptar. La adaptabilidad de los ciudadanos a las vicisitudes y los cambios del sistema de mercado es un principio fundamental de la moral cívica del neoliberalismo. Los ciudadanos deben reinventarse cada vez que el mercado lo necesite, en este caso siendo más optimistas, más solidarios, menos consumistas y menos demandantes respecto de aquello que del sistema pueden conseguir.

En el conjunto de los spots analizados, se establece una operación discursiva compleja mediante la cual se ponen en primer plano valores, como la solidaridad o el anticonsumismo, que, en principio, podrían ser considerados cívicos, progresistas o críticos respecto del sistema socioeconómico dominante; sin embargo, tales valores se definen de tal manera que 
quedan también articulados al discurso de las élites políticas y económicas. De la misma forma, la alusión, en un spot publicitario, a las asambleas de ciudadanos del $15 \mathrm{M}$ que se realizaban para deliberar sobre la legitimidad de los poderes políticos y la dominación de los poderes económicos, sirve para desactivar el potencial contestatario y alternativo de este movimiento al presentar una asamblea con una forma típica de las del $15 \mathrm{M}$, pero en la que solo se discute sobre las prestaciones de un producto de una marca de telefonía.

Por último, si se comparan los resultados obtenidos en este estudio con los que se presentan en la investigación de Alonso et al. (2011), podemos concluir que en el caso español hay una correspondencia significativa entre los discursos sobre la crisis económica de los ciudadanos y los de los spots publicitarios aquí analizados. Los discursos de los ciudadanos en los que se culpabilizan a sí mismos y apelan a la contención del gasto y la austeridad, identificados por Alonso et al., se relacionan claramente con la narrativa "Vive feliz con lo que tienes". Los discursos ciudadanos de miedo al desempleo y sus consecuencias son la tónica dominante en la narrativa "Somos así de solidarios". Y para acabar, Alonso et al. identifican que varios colectivos presentan una representación acomplejada de la singularidad de lo español, por lo que la narración "Españoles, arriba el ánimo" podría surgir como reacción a esta percepción general ciudadana.

No obstante, si se comparan los resultados obtenidos en este estudio con los que se presentan en el trabajo de Banet-Weiser (2013), se observan claros contrastes. En la publicidad de crisis en los Estados Unidos, siguiendo la épica neoliberal, aparecen protagonistas individuales que pretenden aprovechar la situación de derrumbe económico para, con un espíritu de aventura y conquista, cumplir su sueño de prosperar social y económicamente. Las narrativas que se desarrollan en los spots españoles analizados no presentan la crisis como una oportunidad de cambio, ni como una ocasión para aprovechar las circunstancias y atreverse a ir más allá de lo conocido, ni siquiera en el plano privado o individual. En la publicidad de la crisis en España, por el contrario, hay una apelación a la retirada de los ciudadanos hacia lo básico, hacia las comunidades e identidades elementales y primordiales. Se trata de un movimiento conservador de repliegue hacia los 
mundos de la familia, la pareja, los amigos, el barrio y los vecinos, los compañeros de trabajo, hacia entornos de confianza, de auxilio mutuo y de resistencia compartida. Y por encima de todo ello, hacia lo español, como aquel carácter que iguala a todos y que a todos otorga seguridad porque siempre ha existido y siempre existirá a lo largo de la historia, superando todas las crisis de cualquier clase que se puedan presentar.

\section{Referencias}

Ahn, H., Song, Y. A. \& Sung, Y. (2011). When the going gets tough, ads become straightforward but multi-appealed: The influence of the recession on financial services advertising appeals. Journal of Financial Services Marketing, 16(3-4), 230-243. DOI: 10.1057/fsm.2011.17

Asociación para la Investigación de Medios de Comunicación. (2018).Datos EGM: Resumen general. Recuperado de https://www.aimc.es/ egm/datos-egm-resumen-general/

Alonso, L. E., Fernández Rodríguez, C. J. e Ibáñez Rojo, R. (2011). Del consumismo a la culpabilidad: en torno a los efectos disciplinarios de la crisis económica. Política y Sociedad, 48(2), 353-374. Recuperado de http://revistas.ucm.es/index.php/POSO/article/view/36641

Banet-Weiser, S. (2013). Creando una imagen de marca de la crisis. En M. Castells, J. Caraça y G. Cardoso (Eds.), Después de la crisis (pp. 157-188). Madrid, España: Alianza.

Bassilua, A. (2017). Les structures sémiotiques dans le croisement footballpublicité. Estudos Semióticos, 13, 72-80. DOI: 10.11606/issn.19804016.esse.2017.140740

Boyle, K. \& Mrozowski, D. (Eds.) (2013). The great recession in fiction, film, and television: Twenty-first-century bust culture. Plymouth, RU: Lexington Books. 
Cabezuelo-Lorenzo, F. (2014). El orgullo patrio como estrategia comunicativa en tiempos de crisis. Historia y Comunicación Social, 19, 455466. Recuperado de http://revistas.ucm.es/index.php/HICS/ article/view/45146

Castelló-Martínez, A., Ramos-Soler, I. y Pino Romero, C. del. (2013). El discurso publicitario en la crisis económica: nuevos valores y redes sociales. Historia y Comunicación Social, 18, 657-672. Recuperado dehttp://revistas.ucm.es/index.php/HICS/article/view/43997

Courtés, J. (1980). Introducción a la semiótica narrativa y discursiva. Buenos Aires, Argentina: Hachette.

Courtés, J. (1997). Análisis semiótico del discurso: del enunciado a la enunciación. Madrid, España: Gredos.

Dolezel, L. (1998). Heterocosmica: Fiction and possible worlds. Londres, RU: The Johnsons Hopkins University Press.

Fernández Blanco, E., Alameda García, D. y Martín Martín, I. (2011). Las estrategias publicitarias de las marcas en el contexto de crisis. adComunica. Revista de Estrategias, Tendencias e Innovación en Comunicación, 1, 119-138. Recuperado de http://www.adcomunicarevista. com/ojs/index.php/adcomunica/article/view/12

Floch, J. M. (1991). Sémiotique, marketing et communication: Sous les signes, les stratégies. París, Francia: Presses Universitaires de France.

García López, J. (2015). Publicidad y marginación social: efectos discursivos de la publicidad española actual. Revista de la Asociación Española de Investigación de la Comunicación, 2(4), 12-18. Recuperado de http://www.academia.edu/23360232/ Publicidad_y_marginaci\%C3\%B3n_social._Efectos_discursivos_de_la_publicidad_espa\%C3\%B̄ola_actual 
Greimas, A. J. (1970). En torno al sentido: ensayos semióticos. Madrid, España: Fragua.

Greimas, A.J.y Courtés, J. (1982). Semiótica: diccionario razonado de la teoría del lenguaje. Madrid, España: Gredos.

Kellner, D. (2011). Cultura mediática: estudios culturales, identidad y política entre lo moderno y lo posmoderno. Madrid, España: Akal.

Lee, T. D., Chung, W. \& Taylor, R. E. (2011). A strategic response to the financial crisis: An empirical analysis of financial services advertising before and during the financial crisis. Journal of Services Marketing, 25(3), 150-164. DOI: 10.1108/08876041111129146

Lee, T., Chung, W. \& Paik, C. (2011). Understanding your retirement savings: How the recent economic recession changed advertising in retirement financial services. Journal of Financial Services Marketing, 16 (3-4), 244-262. DOI: 10.1057/fsm.2011.20

Lee, T. D., Taylor, R. E. \& Chung, W. (2011). Changes in advertising strategies during an economic crisis: An application of Taylor's six-segment message strategy wheel. Journal of Applied Communication Research, 39(1), 75-91. DOI: 10.1080/00909882.2010.536846

Mangano, D. \& Marrone, G. (2015). Brand language: Methods and models of semiotic analysis. En G. Rossolatos (Ed.), Handbook of brand semiotics (pp. 46-89). Kassel, Alemania: Kassel University Press.

Martínez Rodrigo, E. y Raya-González, P. (2014). Estrategias publicitarias en @Campofrio_es. En S. Liberal Ormaechea y P. Fernández Perea (Coords.), Últimos estudios sobre publiciad: de "Las Meninas" a los tuits (pp. 531-545). Madrid, España: Fragua.

Martínez, E. y Raya-González, P. (2015). La responsabilidad social corporativa de Campofrío a través de su perfil de Twitter. Prisma So- 
cial: Revista de Investigación Social, 14, 274-301. Recuperado de https://www.redalyc.org/html/3537/353744530009/index.html

Méndiz Noguero, A. y Domínguez Águila, L. (1996). Modelos de consumidor en la publicidad. Málaga, España: Newbook.

Notta, O. \& Vlachvei, A. (2015). Changes in marketing strategies during recession. Procedia Economics and Finance, 24, 485-490. DOI: $10.1016 /$ S2212-5671(15)00615-2

Pineda, A., Pérez de Algaba, C. y Hernández-Santaolalla, V. (2013). La ficción como publicidad: análisis semiótico-narrativo del corporate advertainment. Área Abierta, 13(3), 67-91. Recuperado de http:// revistas.ucm.es/index.php/ARAB/article/view/43354

Pollay, R. W. \& Gallagher, K. (1990). Advertising and cultural values: Reflections in the distorted mirror. International Journal of Advertising, 9(4), 359-372. DOI: 10.1080/02650487.1990.11107165

Pollay, R. W. (1986). The distorted mirror: Reflections on the unintended consequences of advertising. Journal of Marketing, 2(50), 18-36. DOI: $10.1353 /$ asr.2000.0012

Propp, V. (1971). Morfología del cuento. Madrid, España: Fundamentos.

Raya, P. (2017). Estrategias comunicativas de la publicidad de Campofrío en Twitter (Tesis doctoral, Universidad de Granada, Granada, España). Recuperado de https://hera.ugr.es/tesisugr/26755026.pdf

Rodrigo, I. y Rodrigo, L. (2013). La causa social en la creatividad publicitaria. Valores y confianza: los discursos publicitarios en situaciones de crisis. Pensar la Publicidad, 7(2), 253-274. DOI: 10.5209/ rev_PEPU.2013.v7.n2.46177

Rodríguez, A., Gil-Soldevilla, S. y Marzal, J. (2015). La crisis del habitar: cine y publicidad en el branded content Cinergía-Gas Natural Fenosa. Questiones Publicitarias, 1(20), 142-159. DOI: $10.5565 / \mathrm{rev} / \mathrm{qp} .16$ 
Ruiz, F. X. (2009a). Anexo: aportaciones metodológicas. Parrillas de análisis: estructuras narrativas, estructuras enunciativas. Questiones $\mathrm{Pu}$ blicitarias, 3, 294-329. 10.5565/rev/qp.120

Ruiz, F. X. (2009b). El Estado es el producto: publicidad institucional, rutinas discursivas e ideología de Estado. Questiones Publicitarias, 3, 268-293. DOI: 10.5565/rev/qp.119

Ruiz, F. X. \& Oliva, M. (2015). Narrativity approaches to branding. En G. Rossolatos (Ed.), Handbook of brand semiotics (pp. 89-133). Kassel, Alemania: Kassel University Press.

Ruiz, F. X., Pujadas, E., Ferrés, J., Obradors, M., Pérez, Ó. y Casals, A. (2009). La construcción de la imagen pública de los organismos del Estado y la ciudadanía a través de las narraciones de la publicidad institucional televisiva. Questiones Publicitarias, 3, 137-206. DOI: $10.5565 / \mathrm{rev} / \mathrm{qp} .115$

Ryan, M. \& Kellner, D. (1988). Camera politica: The politics and ideology of contemporary Hollywood film. Bloomington, Estados Unidos: Indiana University Press.

Sánchez, L. (1991). Estructuras "semionarrativas" en el lenguaje de los anuncios. Verba: Anuario galego de filoloxia, 18, 545-567. Recuperado de http://hdl.handle.net/10347/3169

Sánchez Revilla, M. Á. (2017). Resumen. Estudio Infoadex: de la inversión publicitaria en España 2017. Madrid, España: Infoadex. Recuperado de http://infoadex.factoriadigitalpremium.es/infoadex3/documentacion/ESTUDIO-COMPLETO-2017.pdf

Shairi, H. R. \& Tajbakhsh, N. (2010). Narrativité et tensivité dans le discours publicitaire de Cillit Bang. Recherches en Langue et littarature francaises, 53(218), 103-116. Recuperado de http://france.tabrizu.ac.ir/article_671_72b9f001138f3bb39fb0cadd73b4bb03.pdf 
Todorov, T. (1966). Les catégories du récit littéraire. Communications, 8(1), 125-151. DOI: $10.3406 /$ comm. 1966.1120

Torres-Romay, E. (2010a). La influencia de la crisis en las estrategias comunicativas de las empresas españolas. FISEC-Estrategias, 14, 3-30. Recuperado de http://www.cienciared.com.ar/ra/doc. php?n=1344

Torres-Romay, E. (2010b). Publicidad y precio: estrategias promocionales como respuesta a la crisis. Revista de Estudos da Comunicação, 11(26), 183-197. 10.7213/rec.v1 1i26.22342

Torres-Romay, E. (2011). Advertcrisis: nuevas estrategias publicitarias para hacer frente a la crisis. En J. Sierra Sánchez y S. Liberal Ormaechea (Coords.), Reflexiones científicas sobre cine, publicidad y género desde la perspectiva audiovisual (pp. 291-308). Madrid, España: Fragua. 